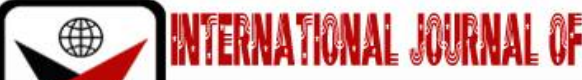

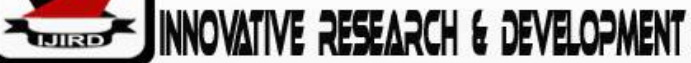

ISSN 2278-0211 (Online)

\section{Pre-service Teachers' Attitude towards the Inclusion of Students with Disabilities}

\author{
Dr. Kahsay Hailu Negash \\ Assistant Professor, Department of Teacher Education \\ Mekelle University, Ethiopia
}

\begin{abstract}
:
The aim of the study was to investigate pre-service teachers' attitudes towards the inclusion of students with disabilities. To conduct the study a descriptive survey research method was used.

The study was conducted in Mekelle University, Ethiopia. In the selection process of the research participants, a convenience sampling method was followed. The data were collected from 143 (92 males and 51 females) preservice/Post Graduate Diploma in Teaching science and non-science teacher candidates. To collect the data for the study, a survey questionnaire was employed. Hence, the data were fully quantitative. Data gathered were analyzed under different themes using a descriptive approach.

The findings of the study showed that though the pre-service teachers have relatively good understanding of students' with disabilities right to education and inclusion, the importance of for students with disabilities, and school roles for inclusion, negative and divided attitudes were found on including students with disabilities in their future classrooms.
\end{abstract}

Keywords: Inclusion, graduate diploma in teaching, pre-service teachers, attitude, disability

\section{Introduction and Background of the Study}

The education of persons with disabilities in Ethiopia dates back to the introduction of Christianity in the $4^{\text {th }}$ A.D and Islam in the 7th A.D. But the modern education, which was introduced to Ethiopia by European missionaries, opened a new chapter in the education of persons with disabilities. In 1917, a school for the blind was opened for the first time. And later, schools for persons with other disabilities such as deaf were opened and now there are many special, regular and inclusive schools.

Ethiopia is one of the signatories of the international agreements, conventions and declaration on the inclusion of persons with special needs in education. Among which, Ethiopia signed the 2006 UN Convention on the Rights of Persons with Disabilities, Universal Declaration of Human Rights (1948), the Convention on the Rights of the Child (1989), the Standard Rules on the Equalisation of Opportunities for Persons with Disabilities (1993) and the Salamanca Framework for Action on Inclusive Education (1994). The country, in its constitution of Article 9 (4) states declared that all agreements ratified by Ethiopia are an integral part of the law of the land.

In addition to this, the country has an Education and Training Policy (1994) which gives place to the education of persons with disabilities. Within this policy, Ethiopia took the initiation further and designed a national strategy framework for special needs/inclusive education strategy in 2006 which again was updated in 2012 for the previous one had a gap and Education Sector Development Programmes (I-IV).

However, despite all the efforts Ethiopia has been making, there is still a gap in the education of persons with disabilities in general and the inclusion of students with disabilities in particular for several reasons. The Ethiopian Ministry of Education (2012), Frank (2015) and Schemer (2017) put that attitude is one of the factors affecting children with disabilities' education. A study by Tirussew (2005) and Gezahegne and Yinebeb (2010) show that negative attitude is one of the challenges for the practice of inclusive education in Ethiopia. Similarly, the United Nations Educational, Scientific and Cultural Organization (UNESCO, 2005) states that negative attitudes of teachers, students and the society are the main challenges to the inclusion of students with disabilities in education. Kassie (2013) states that teachers' attitude towards disability and inclusion is one of the factors affecting the inclusion of students with disabilities. Tefera (1999) argues that if the teachers have negative attitudes, these negative attitudes will have negatively influence the students with disabilities' learning. A study conducted in Ethiopia by Tadesse (2014) shows that the attitude of the school community, which includes teachers, is not positive to include students with disabilities in schools. Actually, there are researches such as by Kahsay (2017) which show that Ethiopian teachers have been developing positive attitudes towards disability and the inclusion of students with disabilities but negative attitude continues to be a challenge to the inclusion of the students with disabilities.

A study by conducted by Tadesse (2014) shows that the attitude of education stakeholders (including teachers) towards the inclusion of students with disabilities is inconsistent throughout schools in Ethiopia. The same is true 
elsewhere in the world. For instance, Beacham and Rouse (2011), who conducted a study in Scotland, found out that preservice teachers have positive attitudes towards including students with disabilities in their classrooms. To the contrary, El-Ashry (2009) conducted a study in Egypt and Sesay (2018) in Sierra Leone found out that pre-service teachers have negative attitudes towards including students with disabilities. On the other hand, a study by Sari, Çeliköz and Seçer (2009) who conducted a research in Turkey reveals that pre-service teachers' attitudes towards including students with disabilities are undecided. This signifies that the inconsistency in the attitudes of teachers including pre-service teachers towards the inclusion of students with disabilities is similar everywhere like in Ethiopia.

A recent study conducted in Ethiopia by Anteneh (2017) reported that there is a positive correlation between teachers' attitudes towards including students with disabilities and their professional development and principal support. This means that the better the teachers are trained on how to include learners with disabilities and receive appropriate support, the better the teachers will develop towards the inclusion of students with disabilities in their classrooms. This research is conducted in Mekelle University in the department of teacher education. The research focused on pre-service teachers' attitude towards the inclusion of students with disabilities. Most of the researches conducted in Ethiopia, as discussed above, focused on in-service teachers' attitudes towards either inclusion or students with disabilities. As to the knowledge of the present researchers, it is hardly to find previous researches conducted in Mekelle University on the attitude of pre-service teachers towards the inclusion of students with disabilities. Hence, the researchers are interested in conducting the current research.

\section{Methodology}

The research used a descriptive survey research method. The research was conducted in the Academic year of 2018/2019 in the Department of Teacher Education, Institute of Pedagogical Sciences at Mekelle University. The department had a total number of 148 pre-service/Post Graduate Diploma in Teaching (PGDT) science (Biology, Information Technology, Chemistry and Physics) and non-science (Civics and Ethical Education, Geography and English Language) candidates who did not take any pedagogical course in their undergraduate studies. The researchers tried to include all the candidates in the research but only 143 of them filled in the questionnaire. Hence, the total number of respondents participated in the research is 143 (92 males and 51 females). All the respondents participated in the research voluntarily.

A questionnaire was employed to collect data from a large number of respondents. The data were collected by the Attitude Scale Related to Inclusion towards Students with Disability which was developed by Beacham and Rouse (2011) and adapted by the researchers to fit the present research aims. The questionnaire consisted 11 items with a Likert scale type marked as Strongly Agree, Agree, Undecided, Disagree, and Strongly Disagree. The data was collected after the PGDT candidates took Inclusive Education course in their final term of pedagogical training to see whether their attitude has been developed positively to include students with disabilities in their future classrooms.

\section{Findings}

\begin{tabular}{|c|c|c|c|c|c|c|c|c|c|c|}
\hline \multirow{2}{*}{ Item } & \multicolumn{2}{|c|}{ SA } & \multicolumn{2}{c|}{ A } & \multicolumn{2}{c|}{ UD } & \multicolumn{3}{c|}{ D } & \multicolumn{2}{c|}{ SD } \\
\cline { 2 - 11 } & No & $\mathbf{\%}$ & No & \% & No & \% & No & \% & No & \% \\
\hline 1 & 92 & 64.3 & 38 & 26.6 & 5 & 3.5 & 1 & 0.7 & 7 & 4.9 \\
\hline 2 & 69 & 48.3 & 50 & 35.0 & 9 & 6.3 & 5 & 3.5 & 7 & 4.9 \\
\hline 4 & 75 & 52.4 & 45 & 31.5 & 4 & 2.8 & 5 & 3.5 & 9 & 6.3 \\
\hline 7 & 73 & 51.0 & 45 & 31.5 & 10 & 7.0 & 3 & 2.1 & 7 & 4.9 \\
\hline
\end{tabular}

Table 1: Pre-Service Teachers' Attitudes towards Students with Disabilities' Rights to Education and Inclusion

Table 1 above shows that most (64.3\%) of the respondents strongly agreed on the concept that education is a right and should be available to all children. Similarly, 75 (52.4\%) and 73 (51\%) respectively responded that students with disabilities can be taught in inclusive classrooms and teachers are responsible for the teaching of all students in the classes they teach. Again, 31.5\% agreed on Item 4 and 7 and 38 (26.65\%) agreed Item 1. However, 10 (7\%), 5 (3.5\%) and 4 (2.8\%) respondents remained undecided on Items 7, 1 and 4 respectively. But it is only $9(6.3 \%)$ of the respondents who strongly disagreed on the teachers' responsibility to teach all students in their classrooms followed by 7 (4.9\%) who strongly disagreed on items which say 'education is a right and should be available to all children' and 'students with disabilities can be taught in inclusive classrooms'. And some 5 (3.5\%) and less disagreed on the items.

Again, from the above figure, it can be comprehended that 69 (48.3\%) strongly agreed and 50 (35\%) agreed that students with disabilities have the right to learn with students without disabilities while some 7 (4.9\%) strongly disagreed and 5 (3.5\%) disagreed with $9(6.3 \%)$ undecided.

\begin{tabular}{|c|c|c|c|c|c|c|c|c|c|c|}
\hline \multirow{2}{*}{ Item } & \multicolumn{2}{|c|}{ SA } & \multicolumn{2}{c|}{ A } & \multicolumn{2}{c|}{ UD } & \multicolumn{3}{|c|}{ D } & \multicolumn{2}{c|}{ SD } \\
\cline { 2 - 11 } & No & $\mathbf{\%}$ & No & \% & No & \% & No & \% & No & \% \\
\hline 3 & 56 & 39.2 & 56 & 39.2 & 8 & 5.6 & 13 & 9.1 & 11 & 7.7 \\
\hline 8 & 31 & 21.7 & 35 & 24.5 & 13 & 9.1 & 36 & 25.2 & 24 & 16.8 \\
\hline 9 & 78 & 54.5 & 44 & 30.8 & 5 & 3.5 & 6 & 4.2 & 7 & 4.9 \\
\hline
\end{tabular}

Table 2: Pre-Service Teachers' Attitudes on the Importance of Inclusion for

Students with Disabilities' Learning 
The above table reveals that $56(39.2 \%)$ of the respondents strongly agreed that students should be grouped according to their ability or disability with another 56 (39.2\%) who expressed their agreement on the statement. But only $13(9.1 \%), 11(7.7 \%)$ and 8 (5.6\%) remained undecided strongly disagreed and disagreed respectively. Again, a dispersed result such as 31 (21.7\%) strongly agreed, 35 (24.5\%) agreed, 13 (9.1\%) undecided, 36 (25.2\%) disagreed and 24 (16.8\%) strongly disagreed that educating students with disabilities in regular classrooms does not make any change to their learning. But majority (54.5\%) strongly agreed and 44 (30.8\%) agreed that educating students with disabilities in regular classroom enables them to develop social life, feeling of independence, and self-confidence while 7 (4.9\%) strongly disagreed, 6 (4.2\%) disagreed and 3.5 remained undecided.

\begin{tabular}{|c|c|c|c|c|c|c|c|c|c|c|}
\hline \multirow{2}{*}{ Item } & \multicolumn{2}{|c|}{ SA } & \multicolumn{2}{c|}{ A } & \multicolumn{2}{c|}{ UD } & \multicolumn{2}{|c|}{ D } & \multicolumn{2}{c|}{ SD } \\
\cline { 2 - 11 } & No & \% & No & \% & No & \% & No & \% & No & \% \\
\hline 5 & 51 & 35.7 & 42 & 29.4 & 7 & 4.9 & 24 & 16.8 & 19 & 13.3 \\
\hline 6 & 31 & 21.7 & 36 & 25.2 & 19 & 13.3 & 31 & 21.7 & 23 & 16.1 \\
\hline
\end{tabular}

Table 3: Pre-Service Teachers' Attitudes towards Including Students with Disabilities in Their Classrooms

According to table 3, 51 (35.7\%) of the respondents strongly agreed and 42 (29.4\%) agreed that teaching students with disabilities in inclusive classes does not waste their time while $24(16.8 \%)$ and 19 (13.3\%) disagreed and strongly disagreed respectively with 7 (4.9\%) undecided. A similar dispersed figure also shows that $36(25.2 \%)$ of the respondents agreed and 31 (21.7\%) strongly agreed that teaching students with disabilities together with other students does not give them comfort while 19 (13.3\%) of them remained undecided. But some 31 (21.7\%) disagreed and 23 (16.1\%) strongly disagreed on the statement that teaching students with disabilities together with other students does not give them comfort and the rest 19 (13.3\%) undecided on it.

\begin{tabular}{|c|c|c|c|c|c|c|c|c|c|c|}
\hline \multirow{2}{*}{ Item } & \multicolumn{2}{|c|}{ SA } & \multicolumn{2}{c|}{ A } & \multicolumn{2}{c|}{ UD } & \multicolumn{3}{c|}{ D } & \multicolumn{2}{c|}{ SD } \\
\cline { 2 - 12 } & $\mathbf{N o}$ & $\mathbf{\%}$ & No & $\mathbf{\%}$ & No & $\mathbf{\%}$ & No & $\mathbf{\%}$ & No & $\%$ \\
\hline 10 & 95 & 66.4 & 31 & 21.7 & 1 & 0.7 & 3 & 2.1 & 9 & 6.3 \\
\hline 11 & 87 & 60.8 & 33 & 23.1 & 3 & 2.1 & 9 & 6.3 & 10 & 7.0 \\
\hline
\end{tabular}

Table 4: Pre-Service Teachers' Attitudes on the Roles of Schools for Inclusion

Table 4 tells that $95(66.4 \%)$ of the respondents strongly agreed and 31 (21.7\%) agreed with 9 (6.3\%) strongly disagreed and 3 (2.1\% disagreed) that schools can help build an inclusive society. Similarly, 87 (60.8\%) strongly agreed followed by $33(23.1 \%)$ agreed that schools are expected to teach students regardless of their background with very few disagreements.

\section{Discussion}

This research tried to investigate pre-service teachers' attitudes towards the inclusion of students with disabilities. The overall results of the study show that pre-service teachers have a good understanding of the right of children to education and inclusion. This corresponds with a study conducted by Ismail, Basheer and Khan (2015) who found out that teachers have good understanding of inclusive education and Beacham and Rouse (2011) who found out pre-service teachers have positive attitudes towards inclusion. The teachers believe that students with disabilities can be taught in inclusive classrooms and have the right to learn with students without disabilities where teachers are also responsible for the teaching of all students in the classes they teach.

According to Monsen, Ewing and Kwoka (2014), teachers' attitudes affect the classroom environment to become inclusive or exclusive. Grieve (2009) also states that there is a variation in the attitude of teachers towards the inclusion of students with disabilities. In this study, most of the pre-service teachers think that students should be grouped according to their disability or ability. This means that the pre-service teachers know the rights of students with disabilities but they don't want the students to teach them in inclusive classes. Again, this contradicts with what the teachers think about the benefits of inclusion for the students' learning. The majority of the pre-service teachers believe that educating students with disabilities in regular classrooms enables them to develop social life, feeling of independence, and self-confidence. On the other hand, most of the pre-service teachers do not consider teaching students with disabilities in inclusive classes wastes their time. But regarding the pre-service teacher's comfort in teaching students with disabilities, a division in the attitude of the pre-service teachers is sought. Less than half of the teacher candidates said that they are comfortable, the other less than half said that they are not comfortable and the rest remained undecided.

Regarding the roles of schools to inclusion, the UNESCO Salamanca Statement (1994) it its Article 2 articulates that inclusive schools are effective means in addressing negative attitudes, creating accepting communities, and creating inclusive society. In this study, the pre-service teachers reported that schools are expected to teach students regardless of their background. In addition, the pre-service teachers have a strong believe that schools can build inclusive society.

\section{Conclusion}

The findings of the study show that pre-service teachers have positive attitudes towards the students with disabilities right to education and inclusion. They have a good believe that students with disabilities can be taught in inclusive classrooms and teachers should take the responsibility to do so. The pre-service teachers also believe that 
teaching students with disabilities in inclusive classes does not waste their time. It can also be concluded that pre-service teachers have a positive belief on the importance of inclusion for the social life, feeling of independence and selfconfidence development for students with disabilities.

The findings of the study also reveal that the pre-service teachers have positive attitudes on the idea that schools should accept students without any sort of discrimination. The pre-service teachers also believe that schools have the power to build inclusive society.

However, according to the findings, pre-service teachers believe that students should be grouped according to their disability or disability. There is also a clear division among the pre-service teachers towards their attitudes whether they are comfortable in teaching students with disabilities.

To sum up, pre-service teachers have positive attitudes towards the inclusion of students with disabilities in most cases but with some negative attitudes. Hence, their feature career could be affected by their present attitudes and these in turn will affect their students' (especially students with disabilities) inclusion.

\section{References}

i. Beacham, N. \& Rouse, M. (2011). Students teachers' attitudes and believes about inclusion and inclusive practice. Journal of Research in Special Educational Needs · 12 (1) 3-11.

ii. El-Ashry, F.K. (2009). General Education Pre-service Teachers' Attitudes toward Inclusion in Egypt. Unpublished doctoral Dissertation, University of Florida, USA. Available at [Accessed on 8 July, 2019].

iii. Frank, B. (2015). Inclusive Education and Children with Disabilities in Ethiopia. Education and Development: University of Denver. Available at https://www.du.edu/korbel/crric/media/documents/brittanyfranck.pdf [Accessed on 10 July, 2019].

iv. Gezahegne, B. \& Yinebeb, T. (2010). Attitudes of teachers towards inclusive education in Ethiopia. Ethiopian Journal of Education and Science, 6(1): 89-96.

v. Grieve, A. M. (2009). Teachers' beliefs about inappropriate behaviour: Challenging attitudes? Journal of Research in Special Educational Needs, 9(3), 173-179. Available at doi:10.1111/j.1471-3802.2009.01130. x. [Accessed on 16 July, 2019].

vi. Ismail, Basheer, and Khan. (2015). Teachers' Attitudes towards Inclusion of Special Needs Children into Primary Level Mainstream Schools in Karachi. The European Journal of Social and Behavioural Sciences. Available at http://dx.doi.org/10.15405/ejsbs.195 [Accessed on 16 July, 2019].

vii. Kassie. S. B. (2013). Inclusive Teaching Involving Visually Impaired Students in English Language Teaching (ELT) Settings. Unpublished Doctoral Dissertation. Andhra University, Visakhapatnam, India.

viii. Ministry of Education, Federal Democratic Republic of Ethiopia (2012). Education statistics annual abstract. Addis Ababa: Ministry of Education: Education Management Education Systems.

ix. Monsen, J. J., Ewing, D. L., \& Kwoka, M. (2014). Teachers' attitudes towards inclusion, perceived adequacy of support and classroom learning environment. Learning Environments Research, 17(1). Available at 113126.doi:10.1007/s10984-013-9144-8 [Accessed on 16 July, 2019].

X. Sari, H. Çeliköz, N. \& Seçer, Z. (2009). An Analysis of Pre-School Teachers' and Student Teachers' Attitudes to Inclusion and their Self-Efficacy. International Journal of Special Education 4(3), 29-44. Available at https://files.eric.ed.gov/fulltext/EJ877918.pdf [Accessed on 16 July, 2019].

xi. Schemer, M. (2017). Education for Children with Disabilities in Addis Ababa, Ethiopia Developing a Sense of Belonging. Switzerland: Springer Open.

xii. Sesay, C. 2018. Teachers' Perceptions and Attitudes Towards Inclusive Education in Sierra Leone. Unpublished doctoral dissertation, Walden University, USA. Available at https://scholarworks.waldenu.edu/dissertations [Accessed on 8 July, 2019].

xiii. Tadesse, Z. (2014). The Knowledge, Attitudes and Practice of Inclusive Education in North Wollo Zone Rural Primary Schools. Unpublished Master's Degree, Indira Gandhi Open University, India. Available at https://scholar.google.ca/scholar?hl=en\&as_sdt=0\%2C5\&q. [Accessed on 10 July, 2019].

xiv. Tefera, T. (1999). Inclusion of Children with Disabilities in Regular Schools: Challenges and Opportunities. The Ethiopian Journal of Education XIX (1), Institute of Educational Research. AAU Printing Press.

xv. Tirussew, T. (2005). Disability in Ethiopia: Issues, insights and implications. Addis Ababa: Addis Ababa University Printing Press.

xvi. United Nations Educational, Scientific and Cultural Organization. (1994). The Salamanca statement and framework for action on special needs education. Salamanca: UNESCO.

xvii. United Nations Educational, Scientific and Cultural Organization (2005). Guidelines for inclusion: Ensuring access to education for all. Paris, UNESCO. 